\title{
Prophylactic adjacent-segment vertebroplasty following kyphoplasty for a single osteoporotic vertebral fracture and the risk of adjacent fractures: a retrospective study and clinical experience
}

\author{
${ }^{*}$ Martin C. Eichler, MD, ${ }^{1}$ Christian Spross, MD, ${ }^{1}$ Alexander Ewers, MD, ${ }^{2}$ Ryan Mayer, BS, ${ }^{3}$ and \\ Fabrice A. Külling, MD' \\ 1Department of Orthopaedics and Traumatology, Kantonsspital St. Gallen, Switzerland; 2Department of Orthopaedics and \\ Traumatolgoy, Spital Herisau, Switzerland; and ${ }^{3}$ School of Medicine, University of California, Irvine, California
}

OBJECTIVE This study investigated the benefit of prophylactic vertebroplasty of the adjacent vertebrae in single-segment osteoporotic vertebral body fractures treated with kyphoplasty.

METHODS All patients treated with kyphoplasty for osteoporotic single-segment fractures between January 2007 and August 2012 were included in this retrospective study. The patients received either kyphoplasty alone (kyphoplasty group) or kyphoplasty with additional vertebroplasty of the adjacent segment (vertebroplasty group). The segmental kyphosis with the rate of adjacent-segment fractures (ASFs) and remote fractures were studied on plain lateral radiographs preoperatively, postoperatively, at 3 months, and at final follow-up.

RESULTS Thirty-seven (82\%) of a possible 45 patients were included for the analysis, with a mean follow-up of 16 months (range 3-54 months). The study population included 31 women, and the mean age of the total patient population was 72 years old (range 53-86 years). In 21 patients (57\%), the fracture was in the thoracolumbar junction. Eighteen patients were treated with additional vertebroplasty and 19 with kyphoplasty only. The segmental kyphosis increased in both groups at final follow-up. A fracture through the primary treated vertebra (kyphoplasty) was found in $4(22 \%)$ of the vertebroplasty group and in $3(16 \%)$ of the kyphoplasty group $(p=0.6)$. An ASF was found in $50 \%(n=9)$ of the vertebroplasty group and in $16 \%(n=3)$ of the kyphoplasty group $(p=0.03)$. Remote fractures occurred in 1 patient in each group $(p=1.0)$.

CONCLUSIONS Prophylactic vertebroplasty of the adjacent vertebra in patients with single-segment osteoporotic fractures as performed in this study did not decrease the rate of adjacent fractures. Based on these retrospective data, the possible benefits of prophylactic vertebroplasty do not compensate for the possible risks of an additional cement augmentation.

http://thejns.org/doi/abs/10.3171/2016.2.SPINE15907

KEY WORDS kyphoplasty; prophylactic; vertebroplasty; adjacent-segment fracture; osteoporotic; thoracic; lumbar

$\mathrm{E}$ VERY year approximately 1.4 million patients suffer from osteoporotic vertebral compression fractures worldwide. ${ }^{14}$ Due to demographic shifts this could become a major health care problem of increasing impact. ${ }^{5}$ The estimated lifetime risk of developing an osteoporotic vertebral fracture in white women is about $15 \%$, and increases up to $27 \%$ in patients over 65 years of age.$^{8,22}$ If treated conservatively, the rate of recurrent fractures ranges from $12 \%$ to $20 \% .^{10}$ The risk of further vertebral fractures depends on several factors, including the number of affected vertebrae and the shape of the prevailing deformities. The risk of further vertebral fractures is 3-fold higher after the first fracture has occurred and increases up to 23 times after the third fracture..$^{20}$

ABBREVIATIONS ASF = adjacent-segment fracture

SUBMITTED August 4, 2015. ACCEPTED February 17, 2016.

INCLUDE WHEN CITING Published online May 6, 2016; DOI: 10.3171/2016.2.SPINE15907.

* Drs. Eichler and Spross contributed equally to this work. 
Kyphoplasty is an option to treat painful osteoporotic compression fractures that do not respond to conservative treatment. ${ }^{31}$ The most frequently observed complication is adjacent-segment fractures (ASFs), with a risk between $2 \%$ and $23 \%$ in kyphoplasty ${ }^{3}$ and up to $52 \%$ in vertebroplasty. ${ }^{13}$ Other complications such as cement leakage (which is mostly asymptomatic), spinal compression with radiculopathy, cement embolism, and infections are rarely observed. ${ }^{17}$ The majority of ASF occurs within 2 months postoperatively. ${ }^{10}$ High preoperative segmental kyphosis, as well as comorbidities such as rheumatoid arthritis, have been found to be risk factors for ASF after kyphoplasty. ${ }^{27}$ Further possible reasons for this increased rate of ASF include the following: amount of cement injected, increased stiffness, load transmission to the adjacent vertebra, and progressing osteoporosis.

The use of prophylactic cement augmentation appears to be a viable option to prevent ASF after kyphoplasty, and biomechanical studies supporting this thesis have been published. ${ }^{7}$ Due to the endplate deflection fracture mechanism ${ }^{9}$ and the load transmission with lower failure strength in the adjacent vertebrae, ${ }^{4}$ these studies suggest building a gradient in mechanical properties through application of the cement near to the neighboring endplate. However, the lack of clinical evidence raises questions about the benefit of a prophylactic vertebroplasty or kyphoplasty. ${ }^{3,19,25}$ To the best of our knowledge, there is no clinical data concerning the rate of ASF after prophylactic vertebroplasty following kyphoplasty. The purpose of the study was to investigate the benefit of prophylactic vertebroplasty in preventing ASF in cases of single-segment osteoporotic vertebral fractures treated with kyphoplasty.

\section{Methods}

\section{Study Population}

We performed a retrospective analysis of medical records and radiographs of all patients who underwent single-segment kyphoplasty at our department from January 2007 to August 2012; the mean follow-up duration of these patients was 16 months. Information about sex, age, hospital stay, fracture level, and complications was collected from medical records and operative protocols.

All patients were admitted to the hospital for a painful single-segment osteoporotic fragility fracture, defined as a fracture after a fall from a standing height or lower that would normally not cause a fracture. Additionally, these patients must have undergone unsuccessful conservative treatment, been symptomatic for less than 6 weeks, and/or had MRI with edema demonstrated in the fractured vertebra. Exclusion criteria included pathological fractures (caused by tumors), incomplete radiographic follow-up (at least 3 months), patients presenting with multiple osteoporotic fractures, patients with a history of prior spinal surgery, and multilevel osteoporotic vertebral body fractures.

All patients were treated with kyphoplasty alone or with additional prophylactic vertebroplasty of the adjacent segment, depending on the surgeon's decision and experience. Kyphoplasty was performed according to the methodology described in the literature. ${ }^{12}$ To prevent higher failure load from too much cement, while still applying enough volume to reinforce the intact vertebral body, the surgeons filled approximately $20 \%$ of its volume with approximately $5 \mathrm{ml}$ of cement using vertebroplasty. ${ }^{28} \mathrm{Ac}-$ cordingly, all included patients were allocated to either the kyphoplasty group or the vertebroplasty group. The fractures were classified according to the AOSpine classification system. ${ }^{21}$ In the vertebroplasty group, the segment to be treated prophylactically was chosen depending on the type of fracture. Fractures that were classified as type A1.2.1 were augmented cranially, and as type A1.2.3 were augmented caudally, whereas fracture types with involvement of both endplates (collapse and complete burst fractures [A1.3, A3.3] as well as pincer fractures [A2.3]) were augmented on both sides (Table 1).

\section{Data Collection}

Patients routinely underwent postoperative follow-up evaluations at 6 weeks and 3 months. The radiographic assessment consisted of standing plain lateral radiographs preoperatively, postoperatively, at 3 months, and at the final follow-up. The local and segmental kyphotic angles were digitally measured according to the method described by Cobb, which has previously been validated to show excellent intrarater and interrater reliability ${ }^{6,34}$ (Figs. 1 and 2). The local kyphosis was defined as the angle between the upper and lower endplates of the fractured vertebra, whereas the segmental kyphosis was defined as the angle between the upper and lower endplates of the intact adjacent vertebral bodies. The occurrence of new vertebral fractures was assessed for all patients. All measurements were performed by the first 3 authors and verified by repeated measurement conducted by the first and last author. If discordant values were observed, a consensus

TABLE 1. AO classification of thoracolumbar fractures*

\begin{tabular}{|c|c|c|c|c|c|c|c|c|}
\hline \multicolumn{9}{|c|}{ Type A. Vertebral body compression } \\
\hline \multicolumn{3}{|c|}{ A1 Impaction fractures } & \multicolumn{3}{|c|}{ A2 Split fractures } & \multicolumn{3}{|c|}{ A3 Burst fractures } \\
\hline $\begin{array}{c}\text { A1.1. } \\
\text { Endplate }\end{array}$ & $\begin{array}{c}\text { A1.2. } \\
\text { Wedge }\end{array}$ & $\begin{array}{c}\text { A1.3. } \\
\text { Vertebral body } \\
\text { collapse }\end{array}$ & $\begin{array}{c}\text { A2.1. } \\
\text { Sagittal }\end{array}$ & $\begin{array}{l}\text { A2.2. } \\
\text { Coronal }\end{array}$ & $\begin{array}{l}\text { A2.3. } \\
\text { Pincer }\end{array}$ & $\begin{array}{c}\text { A3.1. } \\
\text { Incomplete }\end{array}$ & $\begin{array}{c}\text { A3.2. } \\
\text { Burst-split }\end{array}$ & $\begin{array}{c}\text { A3.3. } \\
\text { Complete }\end{array}$ \\
\hline & A1.2.1 Superior & & & & & A3.1.1 Superior & A3.2.1 Superior & A3.3.1 Pincer \\
\hline & A1.2.2 Lateral & & & & & A3.1.2 Lateral & A3.2.2 Lateral & A3.3.2 Complete flexion \\
\hline & A1.2.3 Inferior & & & & & A3.1.3 Inferior & A3.2.3 Inferior & A3.3.3 Complete axial \\
\hline
\end{tabular}

* The AO classification also includes: Type B, anterior and posterior element injury with distraction; and Type C, anterior and posterior element injury with rotation. 


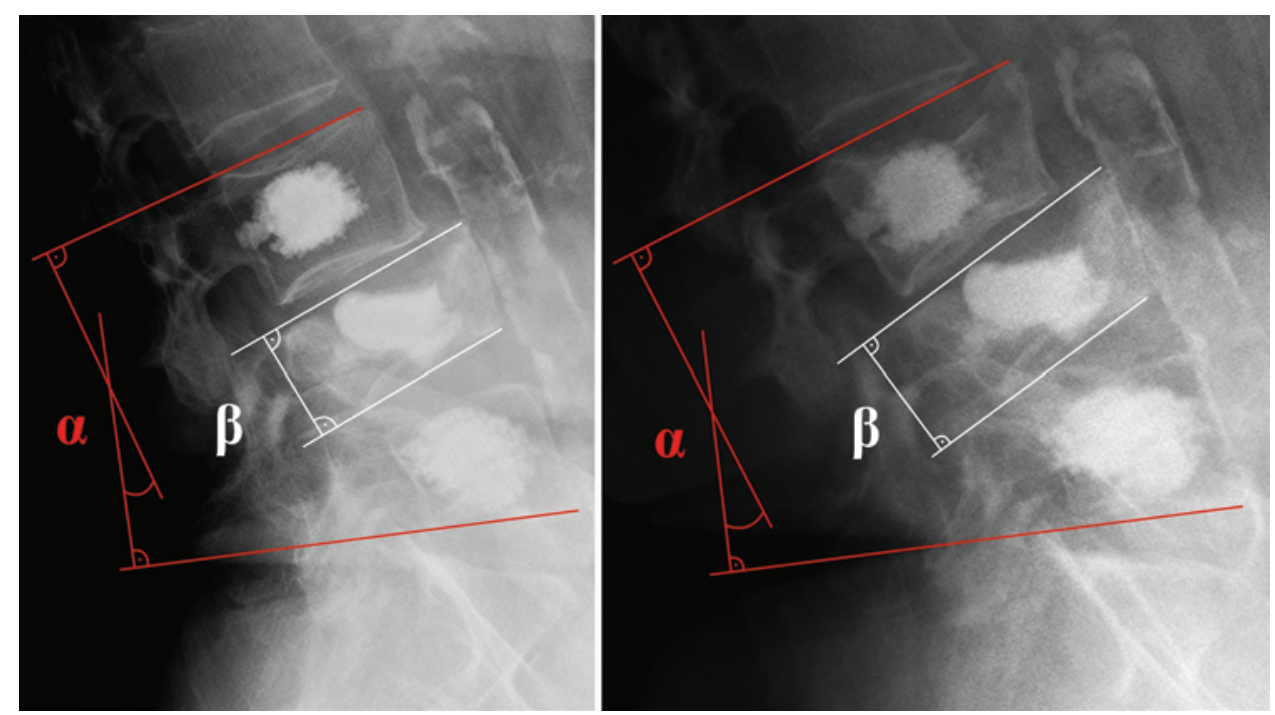

FIG. 1. Standing lateral radiographs obtained immediately postoperatively (left) and at the last follow-up (right) showing an ASF in the prophylactic augmented vertebral body. Measurement of the local $(\alpha)$ and segmental $(\beta)$ kyphosis using the Cobb method is also shown. Figure is available in color online only.

was obtained by measuring the endplates together to determine the correct angle.

\section{Statistical Analysis}

A t-test for comparisons of continuous variables between the 2 groups and a chi-square or Fisher's exact test were used for categorical variables. The level of significance was set to $\alpha=0.05$ throughout the study. The present study was approved by our institutional review board (Kantonale Ethikkommission St. Gallen).

\section{Results}

A total of 45 patients met the inclusion criteria. Of these
45 patients, 2 died prior to achieving complete follow-up, 2 patients were lost to follow-up, and 4 patients had incomplete radiographic follow-up because only a preoperative MR image was obtained without a lateral radiograph. Finally, 37 patients (84\%; 31 women and 5 men) with a mean follow-up duration of 16 months were eligible to be included in the study. The general patient characteristics of the 2 groups are listed in Table 2.

The descriptive and radiographic data are outlined in Tables 2 and 3. In the vertebroplasty group, 6 prophylactic vertebroplasties were performed above the fractured vertebra and 12 on both of the adjacent levels above and below. In the vertebroplasty group there was a nonsignificant tendency toward older age $(\mathrm{p}=0.06)$ and significantly
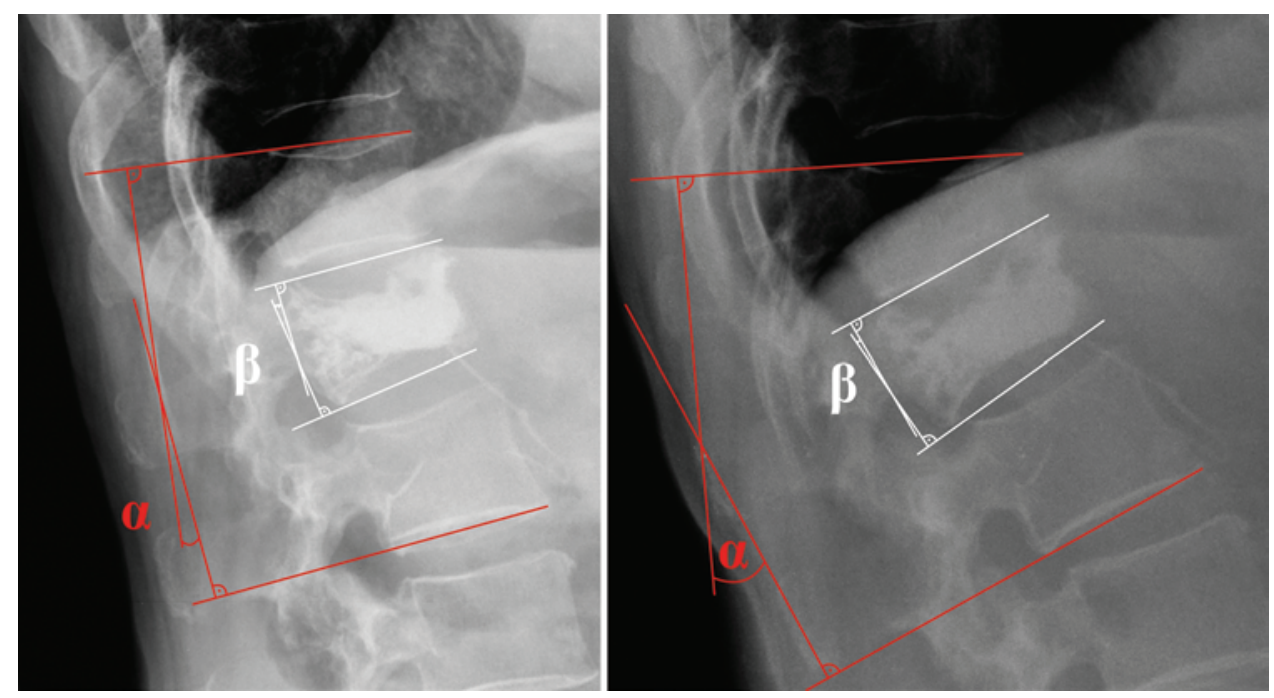

FIG. 2. Standing lateral radiographs obtained immediately postoperatively (left) and at the last follow-up (right) showing an ASF in a nonprophylactically augmented vertebral body. Measurement of the local $(\alpha)$ and segmental $(\beta)$ kyphosis using the Cobb method is also shown. Figure is available in color online only. 
TABLE 2. Descriptive data

\begin{tabular}{lcccc}
\hline \multicolumn{1}{c}{ Variable } & Total & Vertebroplasty Group & Kyphoplasty Group & $p$ Value \\
\hline No. of patients & 37 & 18 & 19 & - \\
\hline Females (\%) & $31(84)$ & 18 & $69(53-86)$ & $0.01^{*}$ \\
\hline Mean age in yrs (range) & $72(53-86)$ & $75(62-86)$ & $6(3-13)$ & 0.3 \\
\hline Mean hospital stay in days (range) & $7.5(2-49)$ & $9(2-49)$ & $17(3-53)$ & 0.8 \\
\hline Mean follow-up in mos (range) & $16(3-53)$ & $15(3-48)$ & & 0.3 \\
\hline Fracture level (\%) & & & & 0.7 \\
\hline T10-L2 & $21(57)$ & $11(61)$ & $2(10)$ & 0.5 \\
\hline T6-8 & $5(13)$ & $3(17)$ & $7(37)$ & - \\
\hline L3-5 & $11(30)$ & $4(22)$ & & - \\
\hline AO classification & & & & - \\
\hline A1.2.1 & 14 & 6 & 6 & - \\
\hline A1.2.3 & 1 & 0 & 2 & - \\
\hline A1.3 & 15 & 9 & 1 & - \\
\hline A3.1 & 4 & 2 & 1 & - \\
\hline A3.2 & 1 & 0 & 1 & \\
\hline A3.3 & 2 & & & \\
\hline - = not applicable. & & & & -
\end{tabular}

more women. There were no significant differences concerning hospital stay, follow-up duration, and fracture location between the 2 groups (Table 2).

The initial local kyphosis was significantly higher in the vertebroplasty group compared with the kyphoplasty group (Table 3). We could observe a corresponding but nonsignificant tendency for segmental kyphosis. When

TABLE 3. Radiographic data of the 2 groups

\begin{tabular}{|c|c|c|c|}
\hline Radiographic Variable & $\begin{array}{l}\text { Vertebroplasty } \\
\text { Group }\end{array}$ & $\begin{array}{l}\text { Kyphoplasty } \\
\text { Group }\end{array}$ & $\begin{array}{c}\mathrm{p} \\
\text { Value }\end{array}$ \\
\hline Mean local preop kyphosis $\left(^{\circ}\right)$ & 20 & 12 & $0.005^{*}$ \\
\hline Mean local postop kyphosis $\left(^{\circ}\right)$ & 11 & 8 & 0.2 \\
\hline $\begin{array}{l}\text { Mean local kyphosis at final } \\
\text { follow-up }\left(^{\circ}\right)\end{array}$ & 15 & 10 & $0.05^{*}$ \\
\hline $\begin{array}{l}\text { Mean preop segmental } \\
\text { kyphosis }\left({ }^{\circ}\right)\end{array}$ & 22 & 14 & 0.07 \\
\hline $\begin{array}{l}\text { Mean postop segmental } \\
\text { kyphosis }\left({ }^{\circ}\right)\end{array}$ & 19 & 13 & 0.1 \\
\hline $\begin{array}{l}\text { Mean segmental kyphosis at } \\
\text { final follow-up }\left(^{\circ}\right)\end{array}$ & 24 & 23 & 0.7 \\
\hline $\begin{array}{l}\text { No. of re-fractures in the } \\
\text { primary cemented vertebral } \\
\text { body }(\%)\end{array}$ & $4(22)$ & $3(16)$ & 0.6 \\
\hline $\operatorname{ASF}(\%)$ & $9(50)$ & $3(16)$ & $0.03^{*}$ \\
\hline Remote fractures (\%) & $1(6)$ & $1(5)$ & 1.0 \\
\hline Disc cement extrusion (\%) & $5(28)$ & $1(5)$ & 0.06 \\
\hline Spinal cement extrusion (\%) & $2(11)$ & $1(5)$ & 0.5 \\
\hline Neurological complications & 0 & 0 & - \\
\hline
\end{tabular}

* Statistically significant. compared to preoperative values, a slight correction of the local and segmental kyphosis could be revealed in both groups directly postoperatively. However, the segmental kyphosis at the final follow-up exceeded the initial and postoperative values in both groups.

Concerning radiographic complications (Table 3), a significantly higher rate of ASF (50\%) was found in the vertebroplasty group, with 9 fractures observed in the prophylactically cemented vertebral bodies ( 6 above and 3 below the level of kyphoplasty; Fig. 1). In the kyphoplasty group, 3 ASFs (16\%) were found in the adjacent vertebrae (2 above and 1 below the level of kyphoplasty; Fig. 2). The number of discal cement extrusions was marginally, although not significantly, higher in the vertebroplasty group. Both groups were comparable regarding the number of cement fractures through the primary treated vertebra (kyphoplasty), remote fractures, and cement extrusion into the spinal canal. None of the patients had any neurological symptoms before or after the treatment.

\section{Discussion}

Bone augmentation with cement is a widely used procedure to relieve pain in osteoporotic compression fractures that does not respond to conservative treatment. ${ }^{16,31}$ Although kyphoplasty and vertebroplasty are considered safe procedures, complications have been reported. One of the most frequent complications is the development of adjacent vertebrae fractures with an incidence of up to $52 \%$. $14,10,13,15,19,20,27$ This is the first study to question the benefit of prophylactic vertebroplasty adjacent to kyphoplasty for single-segment osteoporotic vertebral body fractures. Interestingly, instead of observing a lower rate of ASF in the vertebroplasty group, we ascertained a significantly higher rate $(50 \%)$ than in the kyphoplasty group 
without vertebroplasty (16\%). However, both groups showed a loss of the slight postoperative correction of local and segmental kyphosis at the final follow-up. Either with or without prophylactic vertebroplasty, a progression of the segmental kyphosis could not have been prevented. The high rate of ASF in the vertebroplasty group raises questions about the benefit of this procedure.

Three main points have been identified that can help explain the trends that were observed in this study. First, a fragility fracture indicates poor bone quality and further fractures may be related to the natural progression of this disease rather than the treatment method. Several studies have shown that after conservatively treated osteoporotic vertebral fractures, further vertebral fractures can be observed at a rate ranging from $12 \%$ to $27 \% .^{13,20,27,29}$

Second, from a biomechanical perspective, the increased stiffness due to the cement can alter the biomechanics of load transfer to the adjacent vertebra, therefore causing strain on the neighboring ones. In their biomechanical study, Chun-Kai et al.7 suggested that prophylactic cement injection into the adjacent vertebra might reinforce an osteoporotic vertebral body, especially when located at the pivot point of the lordotic level. ${ }^{7,11}$ In their recently published laboratory investigation Nagaraja et al..$^{24}$ reported that bone cement injected into vertebral bodies alters the local biomechanics, resulting in increased endplate disruption in treated and adjacent vertebrae. More specifically, it increases subsidence in the posterior regions of the treated endplates and the anterior region of the superior caudal endplate. They argue that this may be the initial mechanism leading to subsequent compression fractures after cement augmentation. Cadaveric studies have shown that the bulge of the endplates plays a major role in the mechanics of the intervertebral joint and has a substantial effect on the stiffness of the disc. ${ }^{2}$ With higher loads the annulus fibers stiffen the disc. Without the endplate bulge, the radial bulge of the disc must considerably increase. This may damage the annulus fibers, leading to a decreased buffer action of the cartilaginous component and therefore may increase the risk of new fracture in the adjacent vertebra.

On the other hand, in their finite element analysis, Villarraga et al..$^{30}$ found only minimal changes in stresses and strains at levels adjacent to a kyphoplasty-treated level. Another important finding was that the stress and strain levels found at the treated levels were within the tolerance limits of cancellous and cortical bone. Molloy and colleagues ${ }^{23}$ reported that strength and stiffness were weakly correlated with the percentage fill volume of cement injected. To restore the strength or the stiffness, $16 \%$ and $29 \%$ of the vertebral body needed to be filled, respectively. Nevertheless, clinically, cement volume is the most important modifiable predictor for pain relief in kyphoplasty, as shown by Roeder and colleagues ${ }^{26}$ from the SWISSspine registry.

Furthermore, the clustering argument shows a higher incident of fractures in the midthoracic (T7-9) and thoracolumbar (T11-L1) regions due to the peculiar forces in this region..$^{32}$ In particular, the midthoracic region is the location of greatest thoracic kyphosis and the thoracolumbar junction represents the articulation of the rigid thoracic spine and relatively mobile lumbar segments. ${ }^{33} \mathrm{All}$ these data support the hypothesis that adjacent vertebral fractures may be related to weakened bone structure (i.e., osteoporosis) rather than the surgical treatment. ${ }^{30}$

Third, if patients are engaging in more activity postoperatively because of pain relief, this may lead to an increased potential of falling and sustaining additional spinal trauma.

However, there is only limited information about the clinical benefit of prophylactic vertebral cement augmentation. To the best of our knowledge there is only 1 study, performed by Becker et al., ${ }^{3}$ that prospectively compares prophylactic kyphoplasty following kyphoplasty of fractured vertebrae. These authors did not observe a reduced rate of adjacent vertebral fracture and doubted a clinical benefit of prophylactic kyphoplasty. Their results are in accordance with our findings, because we observed a significantly higher rate of ASF in our vertebroplasty group compared with the kyphoplasty group. The fact that the adjacent vertebral body can fracture despite cement augmentation raises questions regarding the clinical benefit of prophylactic vertebroplasty.

Furthermore, an additional prophylactic vertebroplasty of the adjacent segment has no influence on the restoration of the sagittal alignment. Kim et al. ${ }^{15}$ demonstrated that the restoration of the vertebral body height is dependent on the fracture but not on the kyphotic angle. There is a lack of information about the restoration of local and segmental kyphosis, especially long-term results. Kim et al. showed no influence, whereas the study by $\mathrm{Li}$ et al. ${ }^{18}$ demonstrated a significant reduction of the kyphosis comparing kyphoplasty and vertebroplasty. ${ }^{15,18}$ There exists no literature about the influence of augmenting the adjacent vertebra on kyphosis reduction.

Our study has several limitations. The major limitation is its retrospective, nonrandomized design. Because there were not strict guidelines for prophylactic vertebroplasty, this resulted in a tendency to include older patients with more kyphotic fractures in the vertebroplasty group. Nevertheless, Spross et al. ${ }^{27}$ showed a higher incidence of adjacent vertebral fractures only in patients with increased segmental kyphosis, which did not significantly differ in the two groups. Local kyphosis could not be identified as a risk factor, although the vertebroplasty group had a tendency to have more kyphotic patients, which was not significant. The small changes in preoperative and followup measurements may be due to observer-related error; however, we tried to eliminate this error by re-measuring the values by the first and last author and finding a consensus in discordant values. Because MR images were not available in all cases, the degree of disc degeneration could not be addressed. Another weakness is the lack of information about the bone density due to the inability to obtain dual-energy x-ray absorptiometry measurements in the inpatient setting because of guidelines established by our health care system. Another limitation is the relatively small number of patients included due to rigid selection of patients (single-segment fractures, without any prior spinal surgery). Furthermore, because the minimal follow-up in our study was only 3 months but ASFs are known to develop mainly in the first 2 months after percutaneous kyphoplasty, ${ }^{10}$ the effective rate of ASF might even be higher 
with a longer follow-up duration. Despite these limitations, we believe that the results of this study are clinically relevant as there is very little information about this topic, and we report a significantly higher rate of ASF in the vertebroplasty group than expected.

\section{Conclusions}

In our retrospective analysis, prophylactic vertebroplasty of adjacent vertebrae did not lower the risk of ASF in patients with single-segment osteoporotic vertebral fractures treated with kyphoplasty. Therefore, subsequent adjacent fractures are more likely related to underlying osteoporosis rather than to the surgical intervention.

This study raises questions regarding the benefit of prophylactic vertebroplasty, yet definitively demonstrating or excluding a causative relationship is difficult. A larger, homogeneous patient population is needed to consider additional risk factors such as fracture age, number of previous fractures, obtained postoperative correction, localization, antiresorptive therapy, and bone mineral density. Therefore, further randomized control trials investigating the efficacy and usefulness of prophylactic cement augmentation in vertebroplasty or kyphoplasty are necessary.

\section{References}

1. Ananthakrishnan D, Berven S, Deviren V, Cheng K, Lotz JC, Xu Z, et al: The effect on anterior column loading due to different vertebral augmentation techniques. Clin Biomech (Bristol, Avon) 20:25-31, 2005

2. Baroud G, Nemes J, Heini P, Steffen T: Load shift of the intervertebral disc after a vertebroplasty: a finite-element study. Eur Spine J 12:421-426, 2003

3. Becker S, Garoscio M, Meissner J, Tuschel A, Ogon M: Is there an indication for prophylactic balloon kyphoplasty? A pilot study. Clin Orthop Relat Res 458:83-89, 2007

4. Berlemann U, Ferguson SJ, Nolte LP, Heini PF: Adjacent vertebral failure after vertebroplasty. A biomechanical investigation. J Bone Joint Surg Br 84:748-752, 2002

5. Burge R, Dawson-Hughes B, Solomon DH, Wong JB, King A, Tosteson A: Incidence and economic burden of osteoporosis-related fractures in the United States, 20052025. J Bone Miner Res 22:465-475, 2007

6. Carman DL, Browne RH, Birch JG: Measurement of scoliosis and kyphosis radiographs. Intraobserver and interobserver variation. J Bone Joint Surg Am 72:328-333, 1990

7. Chiang CK, Wang YH, Yang CY, Yang BD, Wang JL: Prophylactic vertebroplasty may reduce the risk of adjacent intact vertebra from fatigue injury: an ex vivo biomechanical study. Spine (Phila Pa 1976) 34:356-364, 2009

8. Dennison E, Cooper C: Epidemiology of osteoporotic fractures. Horm Res 54 (Suppl 1):58-63, 2000

9. Fahim DK, Sun K, Tawackoli W, Mendel E, Rhines LD, Burton AW, et al: Premature adjacent vertebral fracture after vertebroplasty: a biomechanical study. Neurosurgery 69:733-744, 2011

10. Fribourg D, Tang C, Sra P, Delamarter R, Bae H: Incidence of subsequent vertebral fracture after kyphoplasty. Spine (Phila Pa 1976) 29:2270-2277, 2004

11. Furtado N, Oakland RJ, Wilcox RK, Hall RM: A biomechanical investigation of vertebroplasty in osteoporotic compression fractures and in prophylactic vertebral reinforcement. Spine (Phila Pa 1976) 32:E480-E487, 2007

12. Garfin SR, Yuan HA, Reiley MA: New technologies in spine: kyphoplasty and vertebroplasty for the treatment of painful osteoporotic compression fractures. Spine (Phila Pa 1976) 26:1511-1515, 2001

13. Grados F, Depriester C, Cayrolle G, Hardy N, Deramond $\mathrm{H}$, Fardellone P: Long-term observations of vertebral osteoporotic fractures treated by percutaneous vertebroplasty. Rheumatology (Oxford) 39:1410-1414, 2000

14. Johnell O, Kanis JA: An estimate of the worldwide prevalence and disability associated with osteoporotic fractures. Osteoporos Int 17:1726-1733, 2006

15. Kim KH, Kuh SU, Chin DK, Jin BH, Kim KS, Yoon YS, et al: Kyphoplasty versus vertebroplasty: restoration of vertebral body height and correction of kyphotic deformity with special attention to the shape of the fractured vertebrae. J Spinal Disord Tech 25:338-344, 2012

16. Klazen CA, Lohle PN, de Vries J, Jansen FH, Tielbeek $\mathrm{AV}, \mathrm{Blonk} \mathrm{MC}$, et al: Vertebroplasty versus conservative treatment in acute osteoporotic vertebral compression fractures (Vertos II): an open-label randomised trial. Lancet 376:1085-1092, 2010

17. Lee MJ, Dumonski M, Cahill P, Stanley T, Park D, Singh K: Percutaneous treatment of vertebral compression fractures: a meta-analysis of complications. Spine (Phila Pa 1976) 34:1228-1232, 2009

18. Lin EP, Ekholm S, Hiwatashi A, Westesson PL: Vertebroplasty: cement leakage into the disc increases the risk of new fracture of adjacent vertebral body. AJNR Am J Neuroradiol 25:175-180, 2004

19. Lindsay R, Silverman SL, Cooper C, Hanley DA, Barton I, Broy SB, et al: Risk of new vertebral fracture in the year following a fracture. JAMA 285:320-323, 2001

20. Lunt M, O'Neill TW, Felsenberg D, Reeve J, Kanis JA, Cooper C, et al: Characteristics of a prevalent vertebral deformity predict subsequent vertebral fracture: results from the European Prospective Osteoporosis Study (EPOS). Bone 33:505-513, 2003

21. Magerl F, Aebi M, Gertzbein SD, Harms J, Nazarian S: A comprehensive classification of thoracic and lumbar injuries. Eur Spine J 3:184-201, 1994

22. Melton LJ III, Kan SH, Frye MA, Wahner HW, O'Fallon WM, Riggs BL: Epidemiology of vertebral fractures in women. Am J Epidemiol 129:1000-1011, 1989

23. Molloy S, Mathis JM, Belkoff SM: The effect of vertebral body percentage fill on mechanical behavior during percutaneous vertebroplasty. Spine (Phila Pa 1976) 28:1549-1554, 2003

24. Nagaraja S, Awada HK, Dreher ML, Bouck JT, Gupta S: Effects of vertebroplasty on endplate subsidence in elderly female spines. J Neurosurg Spine 22:273-282, 2015

25. Oakland RJ, Furtado NR, Wilcox RK, Timothy J, Hall RM: Preliminary biomechanical evaluation of prophylactic vertebral reinforcement adjacent to vertebroplasty under cyclic loading. Spine J 9:174-181, 2009

26. Röder C, Boszczyk B, Perler G, Aghayev E, Külling F, Maestretti G: Cement volume is the most important modifiable predictor for pain relief in BKP: results from SWISSspine, a nationwide registry. Eur Spine J 22:22412248, 2013

27. Spross C, Aghayev E, Kocher R, Röder C, Forster T, Kuelling FA: Incidence and risk factors for early adjacent vertebral fractures after balloon kyphoplasty for osteoporotic fractures: analysis of the SWISSspine registry. Eur Spine J 23:1332-1338, 2014

28. Sun K, Liebschner MA: Biomechanics of prophylactic vertebral reinforcement. Spine (Phila Pa 1976) 29:14281435, 2004

29. Trout AT, Kallmes DF: Does vertebroplasty cause incident vertebral fractures? A review of available data. AJNR Am J Neuroradiol 27:1397-1403, 2006 
30. Villarraga ML, Bellezza AJ, Harrigan TP, Cripton PA, Kurtz SM, Edidin AA: The biomechanical effects of kyphoplasty on treated and adjacent nontreated vertebral bodies. J Spinal Disord Tech 18:84-91, 2005

31. Wardlaw D, Cummings SR, Van Meirhaeghe J, Bastian L, Tillman JB, Ranstam J, et al: Efficacy and safety of balloon kyphoplasty compared with non-surgical care for vertebral compression fracture (FREE): a randomised controlled trial. Lancet 373:1016-1024, 2009

32. Wasnich RD: Vertebral fracture epidemiology. Bone 18 (3 Suppl):179S-183S, 1996

33. Panjabi MM, White AA: Physical properties and functional biomechanics of the spine, in Panjabi MM, White AA (eds): Clinical Biomechanics of the Spine, ed 2. Philadelphia: JB Lippincott, 1990, pp 1-76

34. Wu W, Liang J, Du Y, Tan X, Xiang X, Wang W, et al: Reliability and reproducibility analysis of the Cobb angle and assessing sagittal plane by computer-assisted and manual measurement tools. BMC Musculoskelet Disord 15:33, 2014

\section{Disclosures}

The authors report no conflict of interest concerning the materi- als or methods used in this study or the findings specified in this paper.

\section{Author Contributions}

Conception and design: Eichler, Külling. Acquisition of data: Eichler, Spross, Ewers. Analysis and interpretation of data: Eichler, Spross. Drafting the article: Eichler. Critically revising the article: Eichler, Spross, Mayer, Külling. Reviewed submitted version of manuscript: Spross, Külling. Approved the final version of the manuscript on behalf of all authors: Eichler. Statistical analysis: Spross. Study supervision: Külling.

\section{Supplemental Information}

Previous Presentations

Portions of this work were presented in a talk at the 73rd Annual Meeting of the Swiss Orthopaedics Association in June 2013 in St. Gallen, Switzerland.

\section{Correspondence}

Martin Eichler, Kantonsspital St. Gallen, Rorschacherstr. 95, 9007 St. Gallen, Switzerland. email: martin.eichler@kssg.ch. 